\title{
Proposta de enquadramento de corpos hídricos em classes de uso na bacia hidrográfica do Rio Santo Antônio (MG)
}

\author{
Guilherme Barbosa REIS ${ }^{1}$, Vitor de Oliveira ABREU ${ }^{1}$, Micael de Souza FRAGA ${ }^{1}$, \\ Tiago TOZI ${ }^{1}$, Demetrius David da SILVA ${ }^{1}$
}

\author{
${ }^{1}$ Departamento de Engenharia Agrícola, Universidade Federal de Viçosa, Viçosa, MG, Brasil. \\ *E-mail: guilherme.eaa.reis@gmail.com
}

Recebido em março/2018; Aceito em novembro/2018.

\begin{abstract}
RESUMO: O presente trabalho buscou elaborar uma proposta de enquadramento dos corpos hídricos em classes de uso na bacia do rio Santo Antônio, Estado de Minas Gerais. A classificação varia de acordo com a qualidade da água em cinco classes (especial, 1, 2, 3 e 4). Os critérios utilizados para a elaboração do enquadramento foram: uso e a ocupação do solo, finalidades das outorgas, volumes outorgados, vazão mínima de referência e densidade populacional. Para cada critério foi atribuído um peso e o mapa de enquadramento foi gerado a partir da sobreposição dos mapas dos critérios adotados. Devido a limitações nas bases de dados, optou-se por propor o enquadramento apenas para os principais rios da bacia. Para definição das áreas prioritárias de intervenção, o Índice de Conformidade ao Enquadramento (ICE) foi calculado com base no enquadramento obtido para os trechos de rio. Como resultado, os rios Guanhães e Preto do Itambé foram enquadrados nas classes 1 e 2 . O rio do Peixe foi classificado como classe 1 e os rios Santo Antônio e do Tanque foram classificados como classe 2. $\mathrm{O}$ trecho enquadrado na classe 1 do rio Guanhães apresentou a menor média do ICE, sendo considerada área prioritária de intervenção.
\end{abstract}

Palavras-chave: geoprocessamento, planejamento ambiental, recursos hídricos.

\section{Proposal of framing the water bodies in classes of usage in the Santo Antônio river watershed, Minas Gerais state, Brazil}

\begin{abstract}
The present work aims to elaborate a proposal of framing the water bodies in classes of usage in the Santo Antônio river basin, located in the state of Minas Gerais. Classification varies according to water quality in five classes (special, 1, 2, 3 and 4). The criteria used to elaborate the proposal were the usage and occupation of the soil, purposes of the grants, volumes granted, minimum reference flow and population density. For each criterion a weight was attributed, and the framing map was generated from the overlay of the adopted criteria maps. Due to limitations in the databases, it was decided to put foward the framework for the main rivers of the basin. Framing Conformity Index (FCI) was also calculated in order to define priority areas for intervention purposes. As a result, Guanhães and Preto do Itambé rivers were classified in classes 1 and 2. The Peixe river was classified as class 1 and the Santo Antônio and Tanque rivers were classified as class 2. The section classified in class 1 of the Guanhães river was the one that presented lower FCI, therefore intervention measures are necessary.
\end{abstract}

Keywords: environmental planning, geoprocessing, water resources.

\section{INTRODUÇÃO}

A adequada gestão dos recursos hídricos é tema recorrente na atualidade, uma vez que a disponibilidade da água, em especial para fins nobres como o abastecimento humano, tem sofrido restrições significativas em função do comprometimento de seus aspectos qualitativo e quantitativo (CUNHA; CALIJURI, 2010). Sendo assim, viabilizar a utilização da água para as atividades humanas associadas à manutenção dos serviços ambientais e da biodiversidade dos ecossistemas aquáticos representa, sem dúvida, um passo fundamental em direção à sustentabilidade (CUNHA et al., 2013).

Martins et al. (2017) enfatizam que a qualidade das águas deve ser necessariamente conhecida em todos os corpos hídricos pelo motivo de ser um mecanismo capaz de definir estratégias que viabilizem a conservação, a recuperação e o uso racional dos recursos hídricos, reduzindo assim os conflitos e direcionando as atividades econômicas.
Diante disso, uma das ferramentas utilizadas na gestão dos recursos hídricos prevista na Lei $n^{\circ} 9.433 / 1997$ é o enquadramento de corpos de água em classes de uso. $\mathrm{O}$ enquadramento não é apenas uma classificação, mas sim um instrumento de planejamento, uma vez que se baseia nos níveis de qualidade que o corpo d'água deveria ter para atender aos usos preponderantes de água na bacia (BRASIL, 1997).

A classificação de enquadramento dos corpos d'água, estabelecendo as condições e os padrões de lançamento de efluentes, é obtida pela Resolução no 357 , de 17 de março de 2005 (BRASIL, 2005), do Conselho Nacional do Meio Ambiente (CONAMA). Nela são estabelecidas as diretrizes para o estabelecimento das classes de enquadramento a serem utilizadas, levando em consideração a qualidade da água e os usos requeridos.

O enquadramento dos corpos de água em classes de uso permite o link entre a gestão qualitativa e quantitativa dos recursos hídricos, servindo como referência para outros 
instrumentos de gestão, tais como a outorga e cobrança pelo uso da água, assim como para o licenciamento e monitoramento ambiental.

No Brasil, muitos trabalhos têm buscado realizar estudos que ofereçam suporte ao enquadramento de corpos d'água superficiais (CUNHA; CALIJURI, 2010; CALMON et al., 2014; CALMON et al., 2016; FERREIRA et al., 2016; GUIMARÃES et al., 2016; AMORIM et al., 2017). Entretanto, as metodologias utilizadas no suporte ao enquadramento de corpos hídricos superficiais têm se constituído em análises probabilísticas e de violação da classe de enquadramento, sem levar com conta os diversos critérios relevantes no diagnóstico da bacia, tais como os usos preponderantes da água e o cenário de uso e ocupação do solo.

Para agregar maior precisão aos estudos, o uso de técnicas em plataforma de sistema de informação geográfica (SIG) aparece como ferramenta para facilitar a manipulação e análise de dados espaciais (FRAGA et al., 2014; ALMEIDA et al., 2017). Dessa forma, os diversos fatores analisados no enquadramento podem ser incorporados em um mesmo sistema de decisão, contribuindo na precisão e confiabilidade dos resultados.

Para Elesbon et al. (2011), a reprodutibilidade das análises também pode ser garantida no decorrer do tempo quando se trabalha em plataforma SIG, uma vez que o banco de dados nesse sistema atua de forma integrada, podendo ser atualizado de tempo em tempo para as revisões do enquadramento do corpo hídrico em questão.

Com base no exposto e considerando a importância deste instrumento de gestão, buscou-se, por meio de técnicas de geoprocessamento, apresentar um estudo de enquadramento dos corpos de água em classes de uso para a bacia do rio Santo Antônio, Estado de Minas Gerais (MG), a ser implementada em função de critérios relevantes ao enquadramento e do nível de qualidade da água a ser alcançado e/ou mantido ao longo do tempo, bem como identificar as áreas prioritárias de intervenção na bacia, tendo como base a conformidade ao enquadramento.

\section{MATERIAL E MÉTODOS}

\subsection{Caracterização da área de estudo}

O presente estudo foi realizado na bacia hidrográfica do rio Santo Antônio, que possui uma área de $10.774 \mathrm{~km}^{2}$, correspondendo a $15,12 \%$ do território da bacia do Doce (Figura 1). A bacia faz parte da Unidade de Planejamento e Gestão de Recursos Hídricos DO3 (UPGRH DO3), conforme codificação estabelecida pelo estado de Minas Gerais (ECOPLAN-LUME, 2010).

O rio Santo Antônio nasce na serra do Espinhaço e percorre cerca de $280 \mathrm{~km}$ até desaguar no rio Doce. Possui como principais afluentes os rios Guanhães e do Peixe, pela margem esquerda, e rios do Tanque e Preto do Itambé, pela margem direita.

\subsection{Categorização dos critérios adotados e obtenção da} proposta de enquadramento

A definição dos critérios utilizados teve como base informações obtidas em ANA (2009). Sendo assim, os critérios escolhidos para a análise foram: finalidade da outorga, volume outorgado, uso e ocupação do solo, vazão específica e densidade populacional.

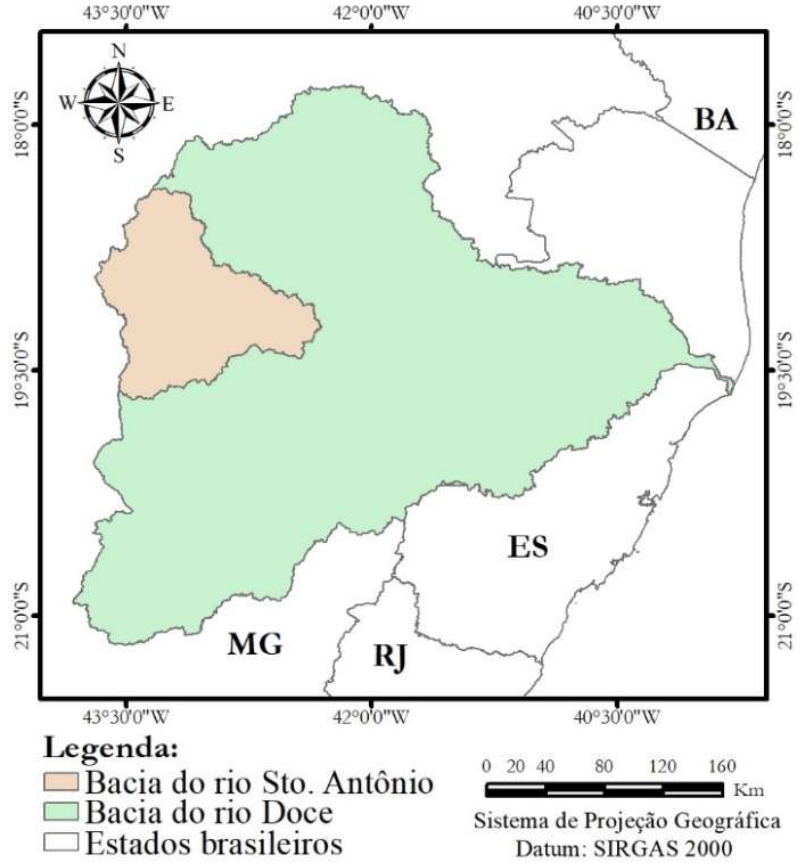

Figura 1. Localização da bacia do rio Santo Antônio.

Figure 1. Location of the Santo Antônio river basin.

Todos os dados obtidos foram transformados em layers de informação em ambiente de SIG utilizando o software ArcGIS 10.2/ArcMap ${ }^{\circledR}$ da ESRI, o que originou uma base de dados para a proposta de enquadramento de cursos de água na bacia do rio Santo Antônio. Na Tabela 1 pode ser observada a fonte dos dados utilizados no estudo.

Tabela 1. Base de dados utilizadas no estudo.

Table 1. Database used in this study.

\begin{tabular}{lc}
\hline \multicolumn{1}{c}{ Base de dados } & Fonte \\
\hline Hidrografia e ottobacias & ANA (2013) \\
Finalidade da outorga & SEMAD (2017) \\
Volume outorgado & SEMAD (2017) \\
Uso e ocupação do solo & ANA (2016) \\
Vazão mínima específica & ELESBON et al. (2014) \\
Densidade populacional & IBGE (2010) \\
\hline
\end{tabular}

Os dados de finalidade e volume outorgados foram obtidos das portarias de outorga referente aos anos de 2013 a 2017. A vazão mínima utilizada por Elesbon et al. (2014) foi a $Q_{7,10}$ por ser a vazão de referência no estado de Minas Gerais para fins de outorga.

No processamento dos dados foi utilizado o arquivo vetorial das ottobacias da bacia do rio Santo Antônio, referente ao nível 6 de ottocodificação. Sendo assim, foi aplicado, em ambiente SIG, um tipo de estatística para cada um dos critérios (Tabela 2), o que resultou em um mapa de enquadramento referente a cada um deles com valores discretizados por ottobacia.

Tabela 2. Tipo de estatística utilizada em cada critério Table 2. Type of statistic used in the evaluated criteria

\begin{tabular}{lc}
\hline \multicolumn{1}{c}{ Critério } & Estatística \\
\hline Finalidade da outorga & Majoritária \\
Volume outorgado & Somatório \\
Uso e ocupação do solo & Majoritária \\
Vazão mínima específica & Média \\
Densidade populacional & Média \\
\hline
\end{tabular}


Posteriormente, os mapas foram reclassificados numa ordem hierárquica de categorias entre 1 e 5 , sendo os maiores números atribuídos às condições mais impactantes para os cursos de água, conforme definição de classes prevista na resolução CONAMA no 357/2005. A categorização dos critérios é apresentada na Tabela 3.

Tabela 3. Relação entre as categorias com as classes de uso da água e os critérios avaliados.

Table 3. Relationship between the categories with the classes of water use and the evaluated criteria.

\begin{tabular}{|c|c|c|}
\hline Categoria & Classe & Descrição \\
\hline \multicolumn{3}{|c|}{ Critério 1: Finalidade da outorga } \\
\hline 1 & Especial & Não considerada \\
\hline 2 & 1 & Consumo humano e animal \\
\hline 3 & 2 & Irrigação e aquicultura \\
\hline 4 & 3 & Consumo industrial \\
\hline 5 & 4 & Demais usos \\
\hline \multicolumn{3}{|c|}{ Critério 2: Volume outorgado $\left(\mathrm{m}^{3}\right)$} \\
\hline 1 & Especial & Não considerada \\
\hline 2 & 1 & 0 a 604,80 \\
\hline 3 & 2 & 604,81 a $2.259,36$ \\
\hline 4 & 3 & $2.259,37$ a $4.689,50$ \\
\hline 5 & 4 & $4.689,50 \mathrm{~m}^{3}$ a $12.038,02$ \\
\hline \multicolumn{3}{|c|}{ Critério 3: Uso e ocupação do solo } \\
\hline 1 & Especial & Vegetação nativa \\
\hline 2 & 1 & Afloramento rochoso \\
\hline 3 & 2 & Reflorestamento \\
\hline 4 & 3 & Pastagem \\
\hline 5 & 4 & Área Urbana \\
\hline \multicolumn{3}{|c|}{ Critério 4: Vazão mínima específica $\left(\mathrm{L} \mathrm{s}^{-1} \mathrm{~km}^{-2}\right)$} \\
\hline 1 & Especial & 2,19 a 2,78 \\
\hline 2 & 1 & 2,79 a 3,37 \\
\hline 3 & 2 & 3,38 a 3,95 \\
\hline 4 & 3 & 3,96 a 4,54 \\
\hline 5 & 4 & 4,55 a 5,13 \\
\hline \multicolumn{3}{|c|}{ Critério 5: Densidade populacional $\left(\mathrm{hab} \mathrm{km}^{-2}\right)$} \\
\hline 1 & Especial & 6 a 8,84 \\
\hline 2 & 1 & 8,85 a 14,24 \\
\hline 3 & 2 & 14,25 a 21,66 \\
\hline 4 & 3 & 21,67 a 50,95 \\
\hline 5 & 4 & 50,96 a 87,57 \\
\hline
\end{tabular}

Nota-se que a categoria 1 , referente a classe especial, não foi considerada para os critérios de uso da água e volume outorgado. Essa ação foi considerada essencial pelo fato de só terem sido analisados 5 anos de dados. Sendo assim, regiões que não apresentaram registro de outorga vigentes poderiam apresentar caso tivesse sido adotado um período maior de análise, o que poderia resultar na classificação das áreas em categorias maiores. Logo, para permitir os usos múltiplos do recurso hídrico e não adotar uma abordagem excessivamente restritiva, optou-se por desconsiderar essa categoria.

Para o peso dos critérios, adotou-se a metodologia utilizada por Monteiro (2016) na avaliação do quão importante cada critério é para a proposta de enquadramento. Essa metodologia tem como base o cruzamento de cada critério estabelecido versus os usos de água preponderantes determinados pela resolução CONAMA $n^{\circ}$ 357/2005. Desta forma, as ponderações foram efetuadas comparando-se a influência de um sobre o outro, avaliando-se em 1 (interferência negativa ou positiva) e 0 (interferência nula). Em seguida realizou-se a ponderação para cada critério, sendo essa obtida pela divisão do total de interferência de cada critério pelo somatório do total de interferências.

Por fim, foi realizada a sobreposição dos mapas de enquadramento, sendo realizado o somatório da multiplicação dos valores de cada critério pelo seu respectivo peso de importância.

Para a adequação do enquadramento à realidade da bacia hidrográfica do rio Santo Antônio utilizou-se as metas de qualidade propostas pelo Plano de Ação de Recursos Hídricos da bacia do rio Santo Antônio (PARH Santo Antônio) (ECOPLAN-LUME, 2010), a eliminação de trechos isolados com classes diferentes e as classes majoritárias por trecho, valendo-se sempre do bom senso para correlacionar as demandas do recurso hídrico com a melhoria da qualidade da água na bacia.

Devido às limitações das bases de dados utilizadas nesse estudo, optou-se por propor o enquadramento apenas para os principais rios da bacia hidrográfica do rio Santo Antônio, sendo estes o próprio rio Santo Antônio (rio principal) e seus maiores afluentes, que segundo o PARH Santo Antônio são, pela margem esquerda, o rio do Peixe e o rio Guanhães e, pela margem direita, o rio do Tanque e o rio Preto do Itambé.

\subsection{Definição das áreas prioritárias de intervenção}

Para definir as áreas prioritárias de intervenção foi utilizado o Índice de Conformidade ao Enquadramento (ICE), que foi desenvolvido pelo Canadian Council of Ministers of the Environment: Water Quality Guidelines (CCME, 2001), sendo atualmente utilizado pela Agência Nacional de Águas (ANA) para avaliar o cumprimento das metas de qualidade das águas dos rios brasileiros definidas pelas classes de uso em que estão enquadrados.

O índice avalia a distância entre a qualidade da água atual e a meta estabelecida pelo enquadramento do corpo hídrico, baseado na comparação dos resultados dos monitoramentos realizados com os valores estipulados pela legislação vigente. O resultado varia de 0 a 100 , sendo divididos em cinco categorias:

- Excelente (95 - 100): as variáveis apresentam-se dentro dos limites estabelecidos durante todo o tempo.

- Bom (80 - 94): a qualidade da água é protegida, apresentando somente um pequeno grau de ameaça e as condições raramente se afastam dos níveis desejáveis.

- Mediano (65 - 79): a qualidade da água geralmente é protegida, mas é ameaçada ocasionalmente, afastando-se, por vezes, dos níveis desejáveis.

- Marginal (45 - 64): a qualidade da água é frequentemente ameaçada ou danificada, as condições muitas vezes se afastam dos níveis desejáveis.

- Ruim (0 - 44): a qualidade da água quase sempre é ameaçada ou danificada, as condições geralmente fogem dos níveis desejáveis.

Para o cálculo do ICE foram utilizados os dados de qualidade de água provenientes das campanhas de monitoramento de qualidade de água do "Projeto Águas de Minas", em operação desde o ano de 1997 e atualmente sob responsabilidade do Instituto Mineiro de Gestão das Águas (IGAM). Para obter o ICE dos anos mais recentes, optou-se por analisar somente os dados entre os anos 2012 a 2016 . Na rede de monitoramento atual, a bacia contém sete estações em operação, sendo que todas elas foram utilizadas no estudo (Tabela 4). 
Tabela 4. Localização das estações de monitoramento de qualidade da água analisados no estudo.

Table 4. Location of the water quality monitoring stations analyzed in the study.

\begin{tabular}{|c|c|c|c|}
\hline \multirow{2}{*}{ Est. } & \multirow{2}{*}{ Corpo Hídrico } & Lat. & Long. \\
\hline & & \multicolumn{2}{|c|}{ (Graus decimais) } \\
\hline RD039 & Rio Santo Antônio & $-19,22$ & $-42,34$ \\
\hline RD077 & Rio Santo Antônio & $-19,07$ & $-43,45$ \\
\hline RD078 & Rio Preto do Itambé & $-19,29$ & $-43,18$ \\
\hline RD079 & Rio do Peixe & $-19,10$ & $-43,17$ \\
\hline RD080 & Rio do Tanque & $-19,28$ & $-43,02$ \\
\hline RD081 & Rio Santo Antônio & $-19,22$ & $-42,88$ \\
\hline RD082 & Rio Guanhães & $-19,05$ & $-42,88$ \\
\hline
\end{tabular}

O índice foi calculado com base nos limites máximos ou mínimos definidos pela Resolução CONAMA n $357 / 2005$ em função da classe de uso em que foram enquadrados os corpos hídricos pela presente metodologia. Sendo assim, delimitou-se a bacia de drenagem para cada estação e as áreas obtidas foram consideradas como áreas de influência das estações.

Os parâmetros para o cálculo do ICE foram selecionados de acordo com o PARH Santo Antônio, que estabeleceu quais seriam os principais indicadores básicos de qualidade da água para a bacia, sendo eles: arsênio total, chumbo total, cobre dissolvido, cor verdadeira, demanda bioquímica de oxigênio (DBO), escherichia coli (E. coli), fósforo total, mercúrio total, oxigênio dissolvido (OD), $\mathrm{pH}$ in loco, turbidez e zinco total.

$\mathrm{Na}$ análise, optou-se por utilizar ambas as frequências (trimestral e semestral) de monitoramento de qualidade da água realizadas pelo IGAM, que totalizam quatro coletas por ano. Não foram consideradas no cálculo do ICE os dados faltantes na base de dados fornecida pelas estações de monitoramento, levando em conta apenas os valores lidos na estação para cada parâmetro.

Como conclusão, as áreas prioritárias de intervenção foram aquelas que apresentaram os menores valores de ICE, dando ênfase a aquelas com ICE não satisfatório (mediano, marginal ou ruim). Para essas áreas, também foram calculadas as porcentagens de violação da classe do enquadramento proposto para as variáveis analisadas no ICE, identificando assim as principais fontes de poluição.

\section{RESULTADOS}

O resultado da ponderação dos critérios levando em consideração a Resolução CONAMA n ${ }^{\circ}$ 357/2005 é apresentado na Tabela 5.

Tabela 5. Resultado da ponderação dos critérios.

Table 5. Result of weighing the criteria.

\begin{tabular}{lc}
\multicolumn{1}{c}{ Critério } & Peso \\
\hline Finalidade da outorga & 0,14 \\
Volume outorgado & 0,16 \\
Uso e ocupação do solo & 0,29 \\
Vazão mínima específica & 0,14 \\
Densidade populacional & 0,27 \\
\hline
\end{tabular}

O resultado da sobreposição dos critérios feita pixel a pixel gerou valores numéricos que variaram de 1,38 a 4,41. Dessa forma, foi feita uma reclassificação estabelecendo uma faixa de pixel para cada classe de enquadramento. Para a classe especial foi considerado o valor do pixel igual a $1 \mathrm{e}$, portanto, esta classe não esteve presente no enquadramento; para a classe 1 valores de 1,38 a 1,99; para a classe 2 valores de 2 a
2,99; para classe 3 valores de 3 a 3,99 e para a classe 4 valores de 4 a 4,41. O resultado dessa reclassificação pode ser observado na Figura 2.

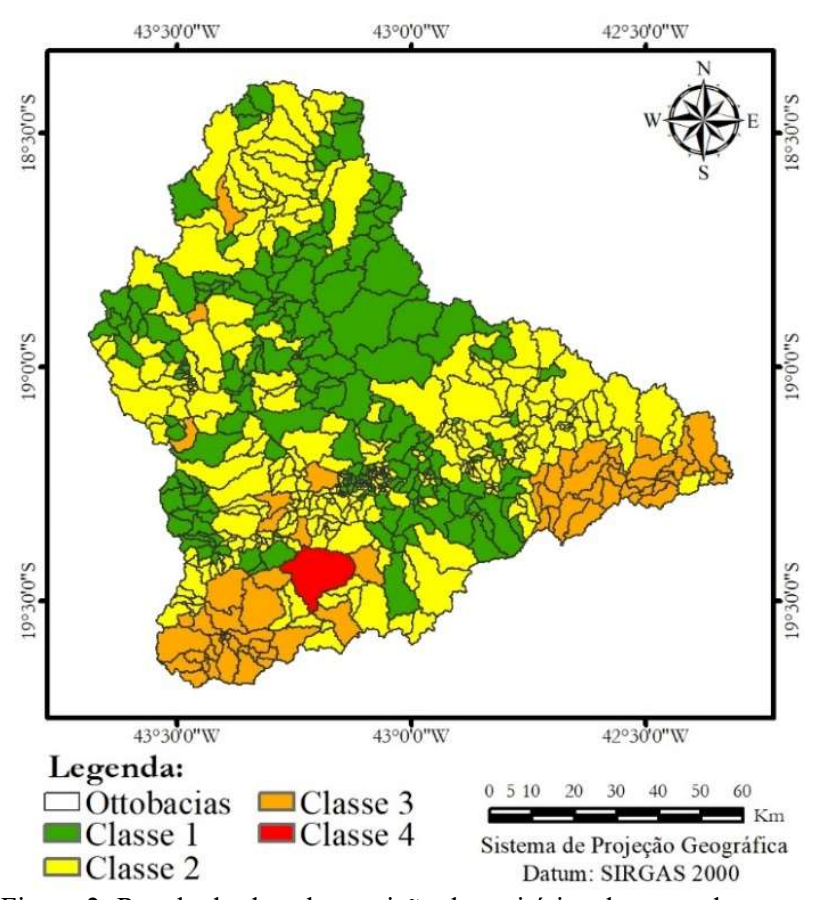

Figura 2. Resultado da sobreposição dos critérios de enquadramento para a bacia do rio Santo Antônio.

Figure 2. Result of the overlapping of the framing criteria for the Santo Antônio river basin.

Com base no mapa da Figura 2 extraiu-se as classes de enquadramento geradas para os principais rios da bacia (rio Santo Antônio, rio do Peixe, rio Guanhães, rio Preto do Itambé e rio do Tanque), obtendo-se o enquadramento preliminar, conforme é demonstrado na Figura 3.

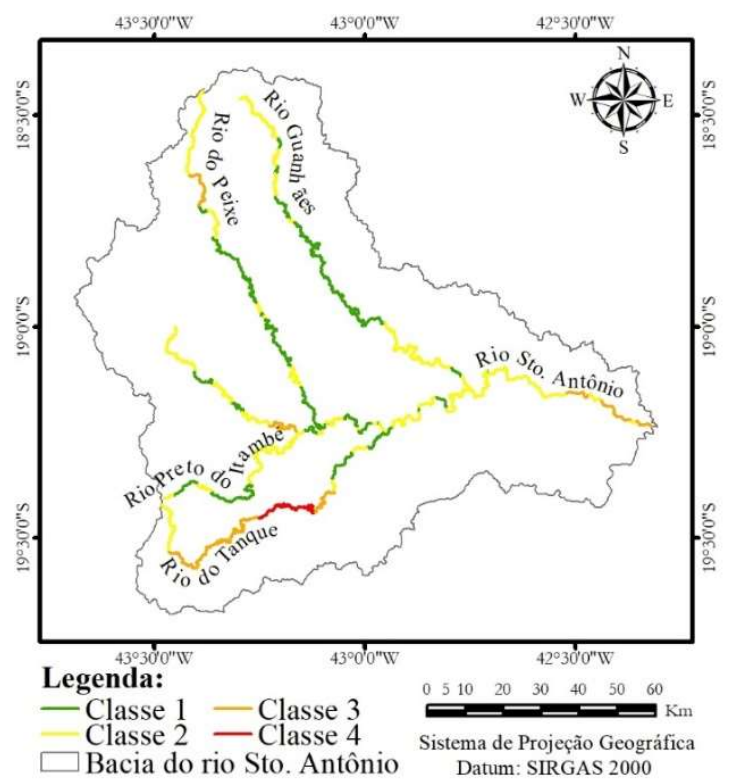

Figura 3. Enquadramento preliminar dos corpos de água em classes de uso para a bacia do rio Santo Antônio.

Figure 3. Preliminary classification of water bodies in use classes for the Santo Antônio river basin.

Após observar os resultados, optou-se por realizar uma adequação utilizando as metas de qualidade propostas pelo 
PARH Santo Antônio. O resultado da adequação é apresentado na Figura 4.

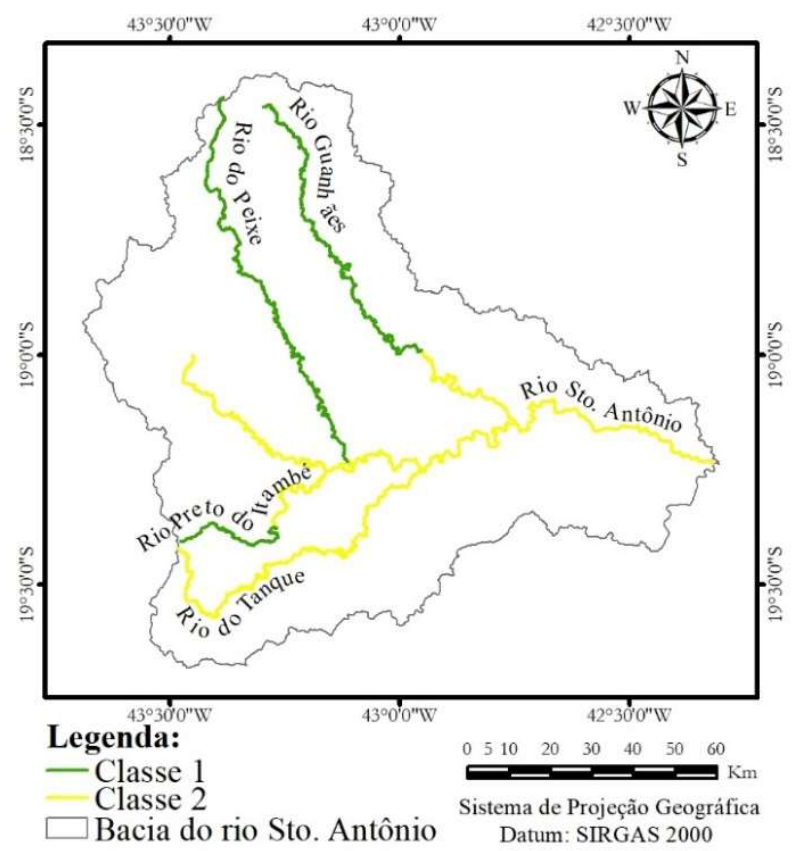

Figura 4. Proposta de enquadramento final dos corpos hídricos na bacia do rio Santo Antônio.

Figure 4. Final proposal for the framing of water bodies in the Santo Antônio river basin.

O mapa de enquadramento final foi dividido em regiões de influência das estações de monitoramento do IGAM, como pode ser observado na Figura 5.

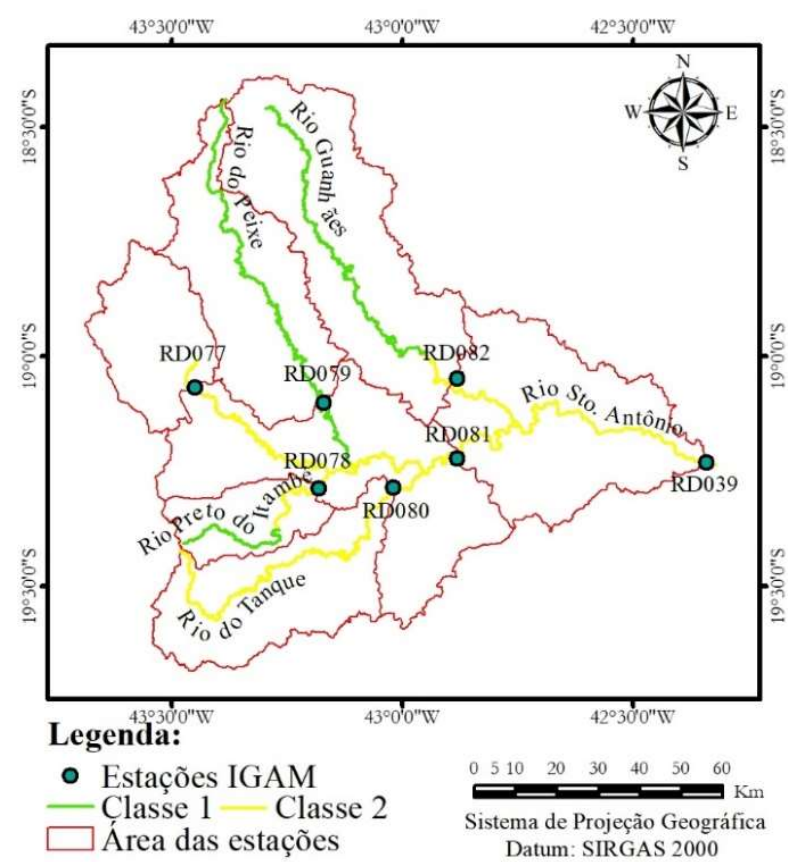

Figura 5. Área de influência das estações de monitoramento do IGAM na bacia do rio Santo Antônio.

Figure 5. Influence area of IGAM monitoring stations in the Santo Antônio river basin.

Com essa divisão foi possível aplicar o ICE comparando o valor dos parâmetros de qualidade da água das estações com os valores limite para cada classe de enquadramento presente no mapa. Os resultados encontrados para o ICE, levando-se em consideração a evolução deste ao longo do tempo, a área de influência de cada estação e as classes de enquadramento presente em cada trecho da hidrografia, são apresentados na Tabela 6. Vale ressaltar que o cálculo do ICE foi realizado utilizando somente os principais indicadores de qualidade da água para a bacia do rio Santo Antônio.

Como pode ser observado, o rio Guanhães apresentou o menor valor médio de ICE dentre todos os resultados obtidos, com um valor igual a 77 (mediano) para o trecho enquadrado como classe 1 . Como o trecho em questão encontra-se dentro da região de influência da estação de código RD082, na Figura 6 é apresentada a percentagem de violação da classe de enquadramento (classe 1) para as variáveis analisadas no ICE, conforme a Resolução CONAMA n 357/2005.

Tabela 6. Resultado do ICE para as estações de monitoramento avaliadas.

Table 6. FCI results for the monitoring stations evaluated.

\begin{tabular}{cccccccc}
\hline \multirow{2}{*}{ Est. } & \multirow{2}{*}{$\mathrm{C}$} & \multicolumn{7}{c}{ ICE } \\
\cline { 3 - 8 } & & 2012 & 2013 & 2014 & 2015 & 2016 & $\mathrm{M}$ \\
\hline RD039 & 2 & 88 & 84 & 100 & 100 & 88 & 92 \\
\hline RD077 & 2 & 86 & 95 & 92 & 100 & 94 & 93 \\
\hline \multirow{2}{*}{ RD078 } & 1 & 63 & 78 & 100 & 95 & 75 & 82 \\
\cline { 2 - 8 } & 2 & 80 & 84 & 100 & 100 & 83 & 89 \\
\hline RD079 & 1 & 52 & 87 & 89 & 95 & 84 & 81 \\
\hline RD080 & 2 & 73 & 82 & 100 & 100 & 100 & 91 \\
\hline \multirow{2}{*}{ RD081 } & 1 & 73 & 94 & 82 & 100 & 100 & 90 \\
\cline { 2 - 8 } & 2 & 92 & 94 & 94 & 100 & 100 & 96 \\
\hline \multirow{2}{*}{ RD082 } & 1 & 51 & 80 & 84 & 92 & 78 & 77 \\
\cline { 2 - 8 } & 2 & 74 & 84 & 94 & 95 & 84 & 86 \\
\hline
\end{tabular}

C: classe de enquadramento; M: média dos valores

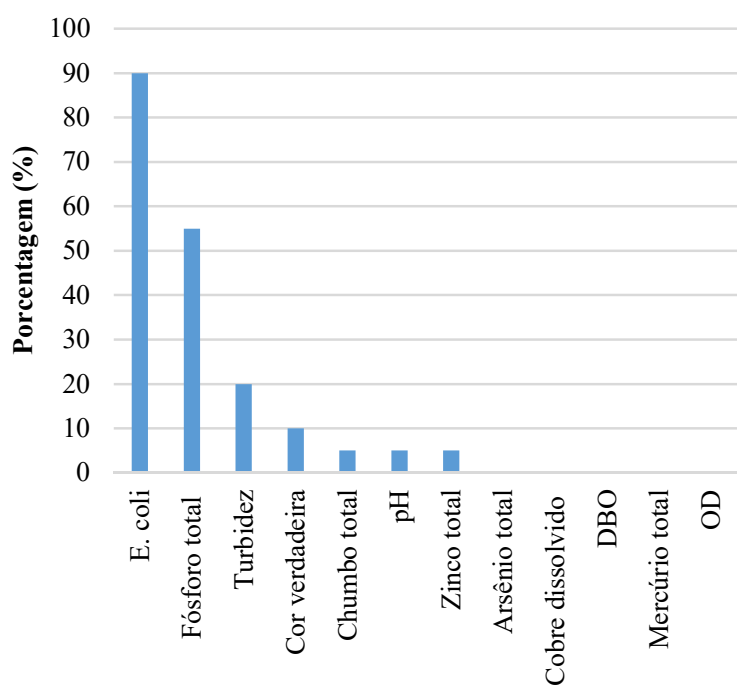

Figura 6. Porcentagem de violação da classe de enquadramento para os dados da estação RD082 conforme a Resolução CONAMA n ${ }^{\circ}$ $357 / 2005$.

Figure 6. Percentage of violation of the class of framing for the database of code station RD082 according to the standards established in CONAMA Resolution No. 357/2005.

\section{DISCUSSÃO}

O enquadramento que resultou na proposta apresentada na Figura 3 se refere às condições ambientais, físico-territoriais e sociais que representam a realidade atual da bacia. Apesar da metodologia utilizada avaliar multicritérios e apresentar um suposto enquadramento ideal para os rios das áreas de drenagem, ainda se faz necessário realizar algumas 
adaptações, visto que o resultado da análise possui pequenos fragmentos isolados com classes diferentes e, muitas vezes, no decorrer de alguns trechos há rios enquadrados em uma classe muito abrangente seguido imediatamente por rio enquadrado em classe mais restritiva. Como exemplo disso temos a região norte da bacia, onde o rio do Peixe passa bruscamente da classe 3 para a classe 1 .

Tendo em vista essa problemática, é necessário realizar uma adequação do enquadramento dos cursos d'água, propondo alterações que visem aumentar a praticidade e viabilidade do mesmo. Segundo a proposição estabelecida no PARH Santo Antônio, a meta de qualidade a ser atingida até o ano de 2030 para o rio Santo Antônio é que a qualidade da água seja compatível com a classe 1 , da nascente até o município de Ferros, e classe 2 deste município até a foz da bacia. No entanto, confrontando essa meta com os resultados obtidos no presente trabalho, optou-se por manter o rio Santo Antônio, em sua totalidade, enquadrado na classe 2, visto que essa é a classe de enquadramento majoritária que foi obtida para o rio, indicando que as condições físico-territoriais, ambientais e sociais analisadas para esse trecho mostram maior compatibilidade com águas de classe 2 conforme a metodologia utilizada.

Para o rio do Peixe, o enquadramento obtido mostrou que o seu trecho mais a montante, próximo à cabeceira, é passível de enquadrado em sua maior parte na classe 2 e seu trecho a jusante, próximo da sua foz, na classe 1. Esta configuração torna o enquadramento pouco consistente e pouco viável visto que é esperado que a qualidade da água de um rio seja melhor nas proximidades de sua nascente, uma vez que ocorrem menores vazões e, consequentemente, menor capacidade de diluição de efluentes (CALMON et al., 2014; GUIMARÃES et al., 2016). Sendo assim, optou-se por eliminar os pequenos fragmentos isolados, enquadrar o primeiro trecho na classe $1 \mathrm{e}$ manter o enquadramento do segundo trecho também nesta classe, o que fez com que o rio do Peixe fosse totalmente enquadrado na classe 1 .

O enquadramento obtido para o rio Guanhães apresentou 3 trechos de classe majoritária. $\mathrm{O}$ trecho mais a montante teve predomínio da classe 2 , no trecho intermediário predominou a classe 1 e no trecho mais próximo da foz a classe 2. Dessa forma, nos dois primeiros trechos foi encontrado o mesmo problema de inconsistência observado no rio do Peixe. Para manter o princípio de que a montante a qualidade da água seja melhor que a jusante, tornando mais viável o enquadramento, alterou-se o trecho 1 de classe 2 para classe 1 . O que fez com que o rio Guanhães fosse enquadrado nas classes 1 , mais a montante, e 2, mais a jusante. Também foi realizada a suavização do enquadramento, eliminando pequenos trechos isolados, assim como também realizado por Monteiro (2016).

O rio Preto do Itambé foi dividido em dois trechos e o enquadramento também foi suavizado mantendo a classe majoritária por trecho. $\mathrm{O}$ trecho a montante foi enquadrado na classe 1 e o trecho à jusante na classe 2 .

$\mathrm{O}$ rio do Tanque foi o que apresentou enquadramento com classes menos restritivas, sendo enquadrado em seu trecho intermediário como classe 4 e em sua maior parte como classe 3. Segundo o PARH Santo Antônio, a vontade da população residente na bacia é que a pior qualidade da água seja classe 2. Portanto, como a efetivação de um enquadramento passa pela consulta pública, optou-se por enquadrar o rio do Tanque na classe 2. Sendo assim, a proposta de enquadramento final para a bacia do rio Santo Antônio é mostrada na Figura 4.
Com relação aos resultados obtidos pelo ICE, é possível observar, na Tabela 6 , que praticamente todos os trechos dos rios analisados estão em conformidade com o enquadramento proposto por este trabalho. Ao analisar as médias, o rio Guanhães apresentou o menor valor de ICE para o trecho enquadrado como classe 1, com um valor igual a 77 . Sendo assim, a conformidade ao enquadramento nesse trecho foi classificada como "mediana", tornando essa área como prioridade de intervenção na bacia do rio Santo Antônio conforme a metodologia utilizada.

Estudos apontam que as principais causas da deterioração da qualidade da água nas bacias hidrográficas são os lançamentos de efluentes domésticos (CALMON et al., 2014; CALMON et al., 2016; OLIVEIRA et al., 2017; COSTA et al., 2018; HANDAM et al., 2018; OLIVEIRA et al., 2018; VARGAS et al., 2018). Como pode ser observado na Figura 6, a maior parte da violação aos limites estabelecidos pelo enquadramento proposto corresponde a escherichia coli e ao fósforo total, indicando que a qualidade da água do rio Guanhães é degradada devido ao despejo de efluentes domésticos sem tratamento adequado. Para Vargas et al. (2018), a poluição difusa oriunda de áreas agrícolas também contribui para o aumento da concentração de fósforo nas águas superficiais. Sendo assim, os resultados obtidos pelos autores supracitados corroboram com os encontrados para o presente trabalho.

No trecho de classe 1, o rio Guanhães sofre influência dos municípios de Santo Antônio do Itambé, Serro, Sabinópolis, Senhora do Porto, Guanhães e Dores de Guanhães. Conforme o estudo publicado no Atlas Esgoto (ANA, 2017), desses municípios, apenas Serro e Guanhães possuem algum índice de atendimento para a coleta e tratamento dos esgotos domésticos.

Gerando uma carga de 715,8 kg DBO dia ${ }^{-1}$ e lançando 233,2 kg DBO dia ${ }^{-1}$, o município de Serro possui um índice de atendimento de aproximadamente $71 \%$. Já no município de Guanhães, esse índice cai para 7,9\%, que corresponde a uma carga gerada de $1450 \mathrm{~kg}$ DBO dia ${ }^{-1}$ e lançada de $1336,3 \mathrm{~kg}$ DBO dia ${ }^{-1}$. Para os demais municípios, toda carga coletada é lançada sem o devido tratamento nos corpos hídricos, demonstrando que o lançamento de efluentes domésticos pode ser sim uma das principais causas da desconformidade com o enquadramento proposto para o rio Guanhães.

No entanto, apesar do forte indício da contaminação através lançamento de esgotos doméstico, as águas superficiais da bacia do rio Doce apresentaram excelentes níveis de DBO e OD. Segundo Andrade et al. (2018), esse fato pode ser justificado pelo processo de autodepuração, que restabelece os níveis de OD, mas não reduz os níveis de coliformes nas águas.

\section{CONCLUSÕES}

A metodologia adotada para fins de enquadramento dos corpos de água em classes de uso na bacia do rio Santo Antônio mostrou-se adequada com a adoção dos critérios analisados. Entretanto, foi necessária uma análise crítica do resultado obtido a fim de eliminar as inconsistências e adequálo às condições mais pertinentes, levando em consideração outros estudos já realizados.

Os rios Guanhães e Preto do Itambé foram enquadrados nas classes 1 e 2, sendo que as zonas de cabeceira foram enquadradas prioritariamente como classe 1 . O rio do Peixe foi classificado como classe 1 em sua totalidade e os rios Santo 
Antônio e do Tanque que foram classificados como classe 2 em toda sua extensão.

A área prioritária de intervenção foi o trecho do rio Guanhães classificado como classe 1, uma vez que apresentou ICE "mediano" ao considerar a média dos valores entre o período analisado.

A alta porcentagem de violação das variáveis escherichia coli e fósforo total na estação RD082 indicam que as condições sanitárias na bacia se mostram predominantemente impróprias, caracterizando o lançamento de efluentes domésticos sem tratamento adequado como a principal fonte de poluição que atua na alteração qualidade das águas do rio Guanhães.

A implementação da proposta de enquadramento dos corpos de água é um esforço importante que garante a manutenção e melhoria da qualidade ambiental da bacia do rio Santo Antônio. Entretanto, por se tratar de técnicas de tratamento de informações espaciais, este trabalho deve ser utilizado para apontar a direção na qual o enquadramento deve seguir, dando uma base de argumentos técnicos aos gestores no momento de elaboração final do enquadramento.

\section{AGRADECIMENTOS}

Os autores agradecem ao Conselho Nacional de Desenvolvimento Científico e Tecnológico (CNPq) pela concessão das bolsas de estudo.

\section{REFERÊNCIAS}

ALMEIDA, L. T.; ABREU, M. C.; FRAGA, M. S.; SILVA, D. D.; CECÍLIO, R. A. Aspectos morfométricos relacionados ao estudo de enchentes na bacia do rio Sapucaí, Minas Gerais. Nativa, Sinop, v. 5, n. 3, p. 169174, 2017. DOI: http://dx.doi.org/10.5935/23187670.v05n03a03

AMORIM, D. G.; CAVALCANTE, P. R. S.; SOARES, L. S.; AMORIM, P. E. C. Enquadramento e avaliação de qualidade da água dos igarapés Rabo de Porco e Precuá, localizados na área da Refinaria Premium I, município de Bacabeira (MA). Engenharia Sanitária e Ambiental, Rio de Janeiro, v. 22, n. 2, p. 251-259, 2017.

ANA_AGÊNCIA NACIONAL DE ÁGUAS). Implementação do Enquadramento em Bacias Hidrográficas no Brasil. Sistema Nacional de Informações sobre Recursos Hídricos - SNIRH. Arquitetura Computacional e Sistêmica. Brasília: ANA, 2009. $150 \mathrm{p}$.

ANA_AGÊNCIA NACIONAL DE ÁGUAS. Base hidrográfica ottocodificada da bacia hidrográfica do Doce. 2013. Disponível em: $<$ http://metadados.ana.gov.br/geonetwork/srv/pt/main.ho me>. Acesso em: 22 mar. 2018.

ANA_AGÊNCIA NACIONAL DE ÁGUAS. Uso e ocupação do solo em moderada resolução espacial $(10 \mathrm{~m})$ da bacia do rio Doce. 2016. Disponível em: $<$ http://metadados.ana.gov.br/geonetwork/srv/pt/main.ho me>. Acesso em: 22 mar. 2018.

ANA_AGÊNCIA NACIONAL DE ÁGUAS. Atlas Esgoto: Despoluição de Bacias Hidrográficas. Brasília: ANA, 2017. $88 \mathrm{p}$.

ANDRADE, L. C.; ANDRADE, R. R.; CAMARGO, F. A. O. The historical influence of tributaries on the water and sediment of Jacuí's Delta, Southern Brazil. Ambiente \& Água - An Interdisciplinary Journal of Applied
Science, Taubaté, v. 13, n. 2, e2150, 2018. DOI: http://dx.doi.org/10.4136/ambi-agua.2150

BRASIL. Lei $n^{\circ}$ 9.433, de 8 de janeiro de 1997. Política Nacional de Recursos Hídricos. Brasília: MMA/SHR, 1997.

BRASIL. Resolução n 357 do Conselho Nacional de Meio Ambiente (CONAMA). Classificação dos corpos de água e diretrizes ambientais para o seu enquadramento, bem como estabelece as condições e padrões de lançamento de efluentes. Brasília: MMA, 2005.

CALMON, A. P. S.; SOUZA, J. C.; REIS, J. A. T.; MENDONÇA, A. S. F. Subsídios para o enquadramento dos cursos de água da bacia hidrográfica do rio Itapemirim considerando aportes de esgotos sanitários. Revista Brasileira de Recursos Hídricos, Porto Alegre, v. 19, n. 1, p. 255-270, 2014. DOI: http://dx.doi.org/10.21168/rbrh.v19n1.p255-270

CALMON, A. P. S.; SOUZA, J. C.; REIS, J. A. T.; MENDONÇA, A. S. F. Uso combinado de curvas de permanência de qualidade e modelagem da autodepuração como ferramenta para o suporte ao processo de enquadramento de cursos d'água superficiais. Revista Brasileira de Recursos Hídricos, Porto Alegre, v. 21, n. 1, p. 118-133, 2016. DOI: http://dx.doi.org/10.21168/rbrh.v21n1.p118-133

CCME_CANADIAN COUNCIL OF MINISTERS OF THE ENVIRONMENT. Canadian water quality guidelines for the protection of aquatic life: CCME Water Quality Index 1.0, Technical Report. 2001.

COSTA, L. A. A.; PESSOA, D. M. M.; CARREIRA, R. S. Chemical and biological indicators of sewage river input to an urban tropical estuary (Guanabara Bay, Brazil). Ecological Indicators, v. 90, p. 513-518, 2018. DOI: https://doi.org/10.1016/j.ecolind.2018.03.046

CUNHA, D. G. F.; CALIJURI, M. C. Análise probabilística de ocorrência de incompatibilidade da qualidade da água com o enquadramento legal de sistemas aquáticos - estudo de caso do rio Pariquera-Açu (SP). Engenharia Sanitária e Ambiental, Rio de Janeiro, v. 15, n. 4, p. 337-346, 2010. DOI: $\quad$ http://dx.doi.org/10.1590/S141341522010000400006

CUNHA, D. G. F.; CALIJURI, M. C.; LAMPARELLI, M. C.; MENEGON JUNIOR, N. Resolução CONAMA 357/2005: análise espacial e temporal de não conformidades em rios e reservatórios do estado de São Paulo de acordo com seus enquadramentos (2005-2009). Engenharia Sanitária e Ambiental, Rio de Janeiro, v. 18, n. 2, p.159-168, 2013. DOI: http://dx.doi.org/10.1590/S1413-41522013000200008

ECOPLAN-LUME. Plano de Ação de Recursos Hídricos da Unidade de Planejamento e Gestão dos Recursos Hídricos Santo Antônio. Belo Horizonte: ECOPLAN/LUME, 2010.99 p.

ELESBON, A. A. A.; GUEDES, H. A. S.; SILVA, D. D.; OLIVEIRA, I. C. Uso de dados SRTM e plataforma SIG na caracterização morfométrica da bacia hidrográfica do braço norte do rio São Mateus - Brasil. Revista Escola de Minas, Ouro Preto, v. 64, n. 3, p. 281-288, 2011. DOI: http://dx.doi.org/10.1590/S0370-44672011000300005

ELESBON, A. A. A.; SILVA, D. D.; SEDIYAMA, G. C.; MONTENEGRO, A. A. A.; RIBEIRO, C. A. A. S.; GUEDES, H. A. S. Proposta metodológica para projeto de redes hidrométricas: Parte I - Espacialização não 
tendenciosa dos dados hidrológicos. Revista Brasileira de Engenharia Agrícola e Ambiental, Campina Grande, v. 18, n. 9, p. 980-985, 2014.

FERREIRA, D. M.; FERNANDES, C. V. S.; KAVISKI, E. Curvas de permanência de qualidade da água como subsídio para o enquadramento de corpos d'água a partir de modelagem matemática em regime não permanente. Revista Brasileira de Recursos Hídricos, Porto Alegre, v. 21, n. 3, p. 479-492, 2016. DOI: http://dx.doi.org/10.1590/2318-0331.011615143

FRAGA, M. S.; FERREIRA, R. G.; SILVA, F. B.; VIEIRA, N. P. A.; SILVA, D. P.; BARROS, F. M.; MARTINS, I. S. B. Caracterização morfométrica da bacia hidrográfica do rio Catolé Grande, Bahia, Brasil. Nativa, Sinop, v. 2, n. 4, p. 214-218, 2014. DOI: http://dx.doi.org/10.14583/23187670.v02n04a05

GUIMARÃES, B. O.; REIS, J. A. T.; MENDONÇA, A. S. F.; AKABASSI, L. Análise probabilística de parâmetros de qualidade da água para suporte ao processo de enquadramento de cursos d'água. Engenharia Sanitária e Ambiental, Rio de Janeiro, v. 21, n. 4, p. 807-815, 2016. DOI: http://dx.doi.org/10.1590/s1413-41522016143190

HANDAM, N. B.; SANTOS, J. A. A.; MORAES NETO, A. H. A.; DUARTE, A. N.; ALVES, E. B. S.; SALLES, M. J.; SOTERO-MARTINS, A. Sanitary quality of the rivers in the Communities of Manguinhos' Territory, Rio de Janeiro, RJ. Ambiente \& Água - An Interdisciplinary Journal of Applied Science, Taubaté, v. 13, n. 1, e2125, 2018. DOI: http://dx.doi.org/10.4136/ambi-agua.2125

IBGE INSTITUTO BRASILEIRO DE GEOGRAFIA E ESTATÍSTICA. Resultados divulgados no Diário Oficial da União em 04/11/2010. 2010. Disponível em: $<$ https://ww2.ibge.gov.br/home/estatistica/populacao/cens o2010/resultados_dou/default_resultados_dou.shtm>. Acesso em: 22 mar. 2018.

MARTINS, G. L. A.; COSTA, A. S. V.; BARROS, A. R.; RAMALHO, F. M. G. Qualidade da água do rio Setúbal em Jenipapo de Minas - MG após construção de barragem. Ambiente \& Água - An Interdisciplinary Journal of Applied Science, Taubaté, v. 12, n. 6, p. 1025-1039, 2018. DOI: http://dx.doi.org/10.4136/ambi-agua.1981
MONTEIRO, F. S. Análise geoespacial como subsídio para proposta de enquadramento de corpos hídricos. 2016. 83f. Trabalho de conclusão de curso (graduação em Engenharia Ambiental) - Universidade do Extremo Sul Catarinense, Criciúma, 2016.

OLIVEIRA, S. C.; AMARAL, R. C.; ALMEIDA, K. C. B.; PINTO, C. C. Qualidade das águas superficiais do Médio São Francisco após a implantação dos perímetros irrigados de Gorutuba/Lagoa Grande e Jaíba. Engenharia Sanitária e Ambiental, Rio de Janeiro, v. 22, n. 4, p. 711-721, 2017. DOI: http://dx.doi.org/10.1590/s1413-41522017136784

OLIVEIRA, D. G.; VARGAS, R. R.; SAAD, A. R.; ARRUDA, R. O. M.; DALMAS, F. B.; AZEVEDO, F. D. Land use and its impacts on the water quality of the Cachoeirinha Invernada Watershed, Guarulhos (SP). Ambiente \& Água - An Interdisciplinary Journal of Applied Science, Taubaté, v. 13, n. 1, e2131, 2018. DOI: http://dx.doi.org/10.4136/ambi-agua.2131

SEMAD_SECRETARIA DE ESTADO DE MEIO AMBIENTE E DESENVOLVIMENTO SUSTENÁTVEL. Outorgas - Relação deferidos, indeferidos, cancelados e outros. 2017. Disponível em: $<$ http://www.meioambiente.mg.gov.br/outorga/relacaodeferidos-indeferidos-cancelados-e-outros $>$. Acesso em: 22 mar. 2018.

VARGAS, R. R.; BARROS, M. S.; SAAD, A. R.; ARRUDA, R. O. M.; AZEVEDO, F. D. Assessment of the water quality and trophic state of the Ribeirão Guaraçau Watershed, Guarulhos (SP): a comparative analysis between rural and urban areas. Ambiente \& Água - An Interdisciplinary Journal of Applied Science, Taubaté, v. $13, \quad$ n. 2, e2170, 2018. DOI: http://dx.doi.org/10.4136/ambi-agua.2170 